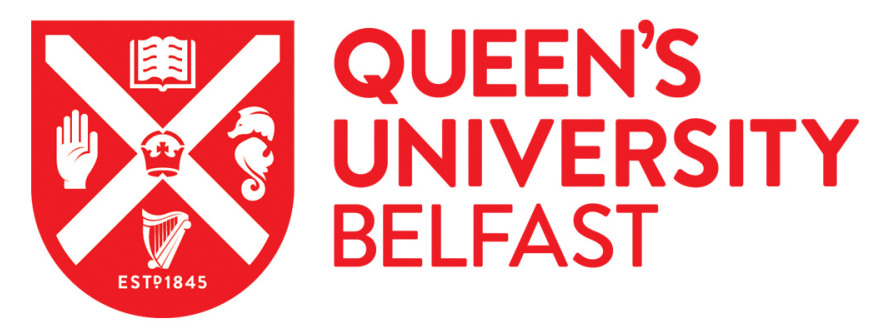

\title{
A prospective comparative evaluation of a Criminal Justice Liaison and Diversion Service in Belfast
}

Scott, D., McGilloway, S., \& Donnelly, M. (2016). A prospective comparative evaluation of a Criminal Justice Liaison and Diversion Service in Belfast. The Journal of Forensic Psychiatry and Psychology, 27(2), $198-214$. https://doi.org/10.1080/14789949.2015.1102313

\section{Published in:}

The Journal of Forensic Psychiatry and Psychology

\section{Document Version:}

Peer reviewed version

\section{Queen's University Belfast - Research Portal:}

Link to publication record in Queen's University Belfast Research Portal

\section{Publisher rights}

(C) 2015 Taylor \& Francis

This is an Accepted Manuscript of an article published by Taylor \& Francis in Journal of Forensic Psychiatry and Psychology on 03/11/2015, available online: http://www.tandfonline.com/10.1080/14789949.2015.1102313

\section{General rights}

Copyright for the publications made accessible via the Queen's University Belfast Research Portal is retained by the author(s) and / or other copyright owners and it is a condition of accessing these publications that users recognise and abide by the legal requirements associated with these rights.

Take down policy

The Research Portal is Queen's institutional repository that provides access to Queen's research output. Every effort has been made to ensure that content in the Research Portal does not infringe any person's rights, or applicable UK laws. If you discover content in the Research Portal that you believe breaches copyright or violates any law, please contact openaccess@qub.ac.uk. 


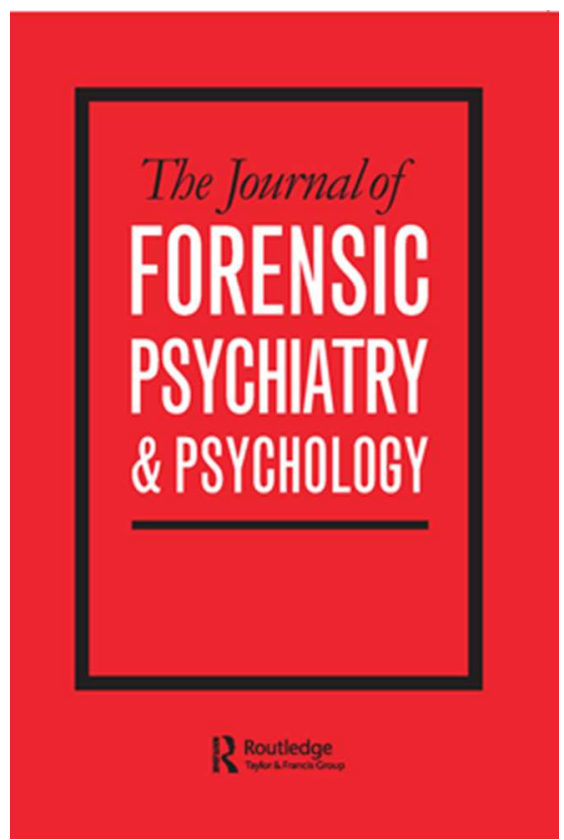

A prospective comparative evaluation of a Criminal Justice Liaison and Diversion Service in Belfast

\begin{tabular}{|r|l|}
\hline Journal: & Journal of Forensic Psychiatry and Psychology \\
\hline Manuscript ID & RJFP-2014-0143.R2 \\
\hline Manuscript Type: & Regular Article \\
\hline Keywords: & $\begin{array}{l}\text { mentally disordered offenders, criminal behaviour, forensic mental health, } \\
\text { offenders, quasi-experimental }\end{array}$ \\
\hline \multicolumn{2}{|l}{} \\
\hline
\end{tabular}

\section{SCHOLARONE ${ }^{m}$}

Manuscripts 
Table 1. Crime related information

\begin{tabular}{|c|c|c|c|c|}
\hline Description & $\begin{array}{c}\text { Intervention station } \\
(n=68)\end{array}$ & $\begin{array}{c}\text { Comparator station } \\
(\mathrm{n}=90)\end{array}$ & Sig & $95 \% \mathrm{Cl}$ \\
\hline \multicolumn{5}{|c|}{ Number of previous convictions } \\
\hline Mean (SD) & $19.63(27.61)$ & $17.63(20.16)$ & .911 & $.906-.917$ \\
\hline Median & 7.50 & 10.00 & & \\
\hline Range & $0-123$ & $0-84$ & & \\
\hline & $n(\%)$ & $n(\%)$ & & \\
\hline \multicolumn{5}{|l|}{ Offence } \\
\hline 0 offences & $13(19)$ & $15(17)$ & .512 & $.502-.522$ \\
\hline $1-5$ offences & $14(21)$ & $18(20)$ & & \\
\hline 6-10 offences & $12(18)$ & $14(16)$ & & \\
\hline $11-20$ offences & $4(6)$ & $14(16)$ & & \\
\hline$>20$ offences & $19(28)$ & $28(31)$ & & \\
\hline Not known & $6(9)$ & $1(1)$ & & \\
\hline \multicolumn{5}{|c|}{ Nature of current offence(s) } \\
\hline $\begin{array}{l}\text { Offence against the } \\
\text { person }\end{array}$ & $28(41)$ & $56(62)$ & .173 & $.210-.227$ \\
\hline Acquisitive offence & $21(23)$ & $23(25)$ & .851 & $1.00-1.00$ \\
\hline Miscellaneous & $12(18)$ & $25(28)$ & .017 & $.023-.029$ \\
\hline $\begin{array}{l}\text { Destructive } \\
\text { property offence }\end{array}$ & $8(12)$ & $21(23)$ & * & \\
\hline Public order offence & $8(12)$ & $7(8)$ & * & \\
\hline Sexual offence & $7(10)$ & $2(2)$ & * & \\
\hline Missing & $3(4)$ & $2(2)$ & * & \\
\hline \multicolumn{5}{|c|}{ Nature of previous offence(s) } \\
\hline Acquisitive offence & $139(28)$ & $199(33)$ & .212 & $.220-.236$ \\
\hline $\begin{array}{l}\text { Offence against the } \\
\text { person }\end{array}$ & $80(16)$ & $165(27)$ & .160 & $.215-.231$ \\
\hline Miscellaneous & $67(14)$ & $78(13)$ & .948 & $1.000-1.000$ \\
\hline $\begin{array}{l}\text { Destructive } \\
\text { property offence }\end{array}$ & $49(10)$ & $84(14)$ & .632 & $.698-.716$ \\
\hline Public order offence & $54(11)$ & $73(12)$ & .379 & $.458-.477$ \\
\hline Sexual offence & $10(2)$ & $10(2)$ & .593 & $.764-.780$ \\
\hline Missing & $18(4)$ & $16(3)$ & * & \\
\hline
\end{tabular}

1. Cramer's V

2. Phi

*. Statistical analysis was not possible due to small numbers 


\section{Table 2. Change in BPRS scores over time}

\begin{tabular}{|c|c|c|c|c|}
\hline Description & $\begin{array}{c}\text { Intervention } \\
\text { station }(n=68)\end{array}$ & $\begin{array}{c}\text { Comparator } \\
\text { station }(n=90)\end{array}$ & Sig $^{1}$ & $95 \% \mathrm{Cl}$ \\
\hline $\begin{array}{l}\text { Baseline } \\
\text { Mean (SD) } \\
\text { Median } \\
\text { Range } \\
\text { Six months } \\
\text { Mean (SD) } \\
\text { Median } \\
\text { Range } \\
\text { Sig } \\
95 \% \mathrm{Cl}\end{array}$ & $\begin{array}{c}35.61(7.39) \\
35.5 \\
24-54 \\
\\
\\
38.86(7.27) \\
36.0 \\
27-52 \\
.600 \\
-4.12-2.12\end{array}$ & $\begin{array}{c}40.85(9.59) \\
42.0 \\
25-64 \\
.223 \\
-3.55-.622\end{array}$ & .013 & $-7.09--.47$ \\
\hline
\end{tabular}

Mann-Whitney U test

2. Wilcoxon test 
Table 3. Change in GHQ scores over time

\begin{tabular}{|c|c|c|c|c|}
\hline Description & $\begin{array}{c}\text { Intervention } \\
\text { station }(n=68)\end{array}$ & $\begin{array}{c}\text { Comparator } \\
\text { station }(n=90)\end{array}$ & Sig $^{1}$ & $95 \% \mathrm{Cl}$ \\
\hline & n (\%) & n (\%) & \multirow{5}{*}{.760} & \multirow{5}{*}{$.753-.770$} \\
\hline Baseline & & & & \\
\hline Mean (SD) & $6.60(4.34)$ & $7.14(3.12)$ & & \\
\hline Median & 7.00 & 8.00 & & \\
\hline Range & $0-12$ & $0-12$ & & \\
\hline Six months & & & \multirow{5}{*}{.157} & \multirow{5}{*}{$.150-.164$} \\
\hline Mean (SD) & $4.36(3.27)$ & $5.38(3.43)$ & & \\
\hline Median & 4.00 & 6.00 & & \\
\hline Range & $0-11$ & $0-12$ & & \\
\hline $\begin{array}{l}\text { Sig }^{2} \\
95 \% \mathrm{Cl}\end{array}$ & $\begin{array}{c}.018 \\
.015-.020\end{array}$ & $\begin{array}{c}.001 \\
.000-.000\end{array}$ & & \\
\hline
\end{tabular}

Mann-Whitney U test

2. Wilcoxon test 
Journal of Forensic Psychiatry and Psychology

Page 4 of 30

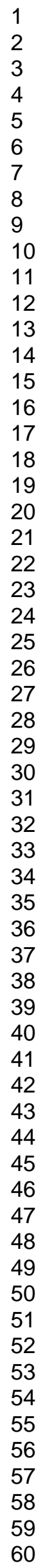

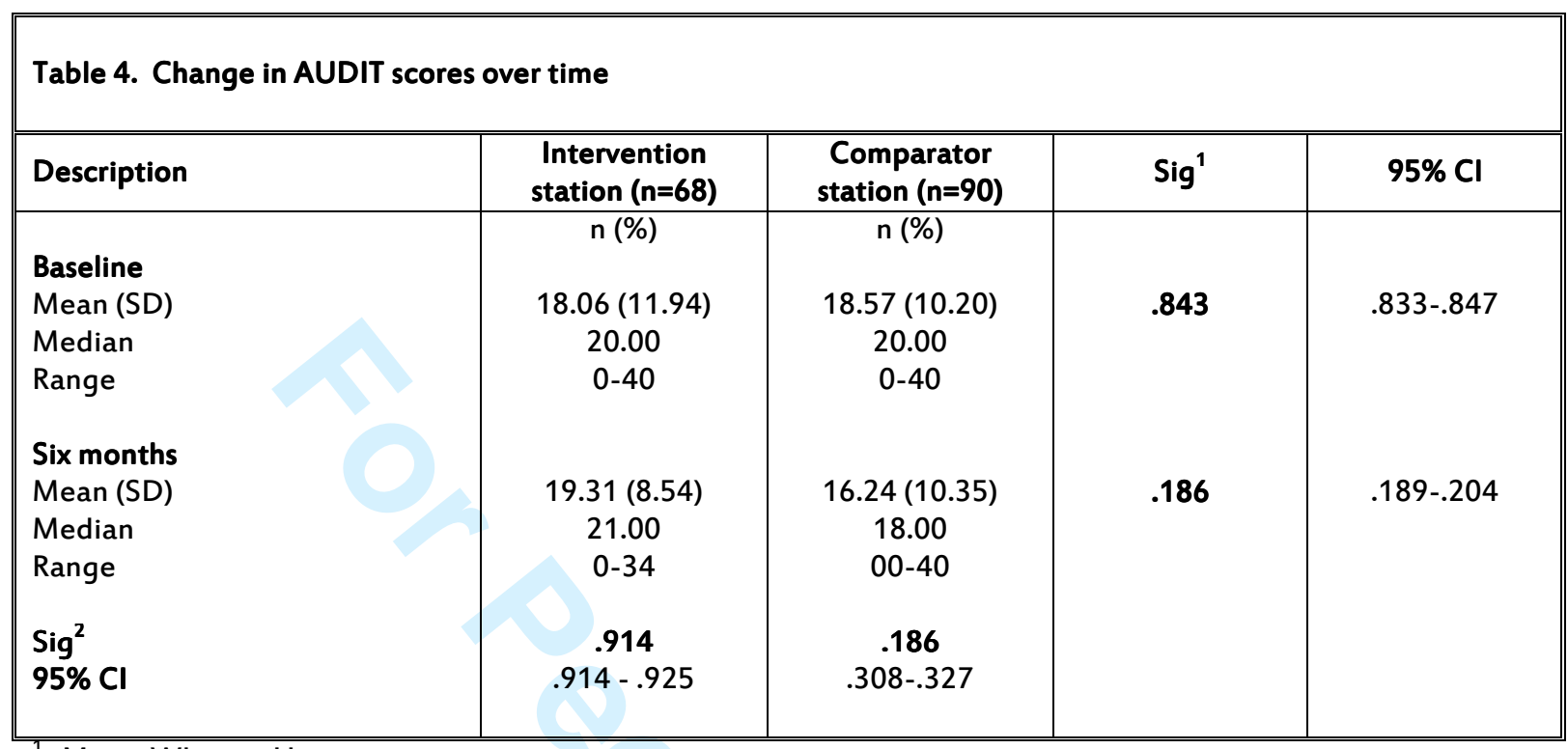

1. Mann-Whitney U test

2. Wilcoxon test

URL: http:/mc.manuscriptcentral.com/rjfp Email: forensic-psychiatry@nottingham.ac.uk 
Table 5. Change in DAST scores over time

\begin{tabular}{|l|c|c|c|c||}
\hline \hline Description & $\begin{array}{c}\text { Intervention } \\
\text { station (n=68) }\end{array}$ & $\begin{array}{c}\text { Comparator } \\
\text { station (n=90) }\end{array}$ & Sig $^{1}$ & $\mathbf{9 5 \%}$ Cl \\
\hline Baseline & $\mathrm{n} \mathrm{( \% )}$ & $\mathrm{n}(\%)$ & .970 & $.967-.974$ \\
Mean (SD) & $5.98(5.07)$ & $6.25(5.34)$ & & \\
Median & 3.00 & 4.50 & \\
Range & $1-17$ & $0-19$ & $.525-.544$ \\
Six months & & & .528 \\
Mean (SD) & $6.28(5.28)$ & $7.31(6.05)$ & & \\
Median & 6.00 & 5.50 & $1-20$ & \\
Range & $0-17$ & .001 & & \\
Sig & .242 & $000-.002$ & & \\
95\% Cl & $.234-.250$ & & \\
\hline
\end{tabular}

Mann-Whitney U test

2. Wilcoxon test 


\begin{tabular}{|c|c|c|c|c|}
\hline Description & $\begin{array}{c}\text { Intervention } \\
\text { station }(n=68)\end{array}$ & $\begin{array}{c}\text { Comparator } \\
\text { station }(n=90)\end{array}$ & $\operatorname{Sig}^{1}$ & $95 \% \mathrm{Cl}$ \\
\hline & $\mathrm{n}(\%)$ & $\mathrm{n}(\%)$ & & \\
\hline \\
\hline Mean (SD) & $20.06(11.49)$ & $16.49(13.74)$ & $p=.141$ & $.133-.147$ \\
\hline Median & 18.18 & 13.64 & & \\
\hline Range & $4.55-50.00$ & $0-55$ & & \\
\hline \multicolumn{5}{|l|}{ Six month social support } \\
\hline Mean (SD) & $17.27(10.30)$ & $15.26(11.48)$ & $p=.375$ & $.372-.391$ \\
\hline Median & 18.18 & 18.18 & & \\
\hline Range & $0-41$ & $0-41$ & & \\
\hline $\begin{array}{l}\text { Sig }^{2} \\
95 \% \mathrm{Cl}\end{array}$ & $\begin{array}{c}p=.846 \\
.839-.853\end{array}$ & $\begin{array}{c}p=.632 \\
.622-.641\end{array}$ & & \\
\hline \multicolumn{5}{|l|}{ Baseline social stress } \\
\hline Mean (SD) & $12.66(10.88)$ & $17.53(10.88)$ & $p=.036$ & $.031-.038$ \\
\hline Median & 11.36 & 18.18 & & \\
\hline Range & $0-41$ & $0-64$ & & \\
\hline \multicolumn{5}{|l|}{ Six month social stress } \\
\hline Mean (SD) & $14.09(9.35)$ & $17.64(10.73)$ & $p=.179$ & $.176-.191$ \\
\hline Median & 13.64 & 18.18 & & \\
\hline Range & $0-32$ & $0-36$ & & \\
\hline $\begin{array}{l}\text { Sig } \\
95 \% \mathrm{Cl}\end{array}$ & $\begin{array}{c}p=.636 \\
.627-.646\end{array}$ & $\begin{array}{c}p=.032 \\
.028-.035\end{array}$ & & \\
\hline
\end{tabular}

1. Mann-Whitney U test

2. Wilcoxon test 


\begin{abstract}
There is continued interest in the planning, development and implementation of services designed to identify, detainees with mental illness and connect them to health and social services. However, currently little is known about how best to configure, organise and deliver these services. The study employed a prospective follow-up design with a comparator group to describe and evaluate a police mental health liaison service based in Belfast.

Participants were recruited from two neighbouring police stations, only one of which provided a mental health liaison service. Outcomes including mental health status, drug and alcohol misuse, risk-related behaviour and 'administrative' outcomes were assessed at the time of arrest and six months later.
\end{abstract}

The service was successful in identifying and assessing detainees though there appeared to be similar between-group levels of mental health problems over time. Results highlight a need to develop firmer linkages and pathways between criminal justice liaison / diversion services and routine health and social services. 


\section{Background}

There is continuing concern regarding the prevalence, nature and treatment of mental illness or mental health problems amongst criminal offenders both nationally (NHS England 2014a; NHS England 2014b) and internationally (Steadman et al., 2014; Callahan, et al., 2013). The challenge of responding to this group has led to the development of a range of services designed to identify Mentally Disordered Offenders (MDOs) and ensure that they receive appropriate treatment. However, despite the widespread implementation of these services, little is known about their effectiveness. In order to address this, the UK government recently commissioned the Offender Health Collaborative, a working group comprising six specialist health and social care, charity and offender organisations, to develop an operating model and standard service specification for such services in England. These more clearly specified services are currently being trialled and evaluated across a range of localities with the intention of informing the development of future service provision that will be in line with NHS England's commissioning priorities (NHS England, 2014a; NHS England, 2014b).

Previously, different jurisdictions have responded to meeting the often complex needs of MDOs in a variety of ways. For example, in the US, drug or mental health courts have been implemented since the late 1980s and early 1990s. However, in the UK, two main types of service have developed either at the courts (known generally as court diversion services), or in police stations (referred to as liaison services). Collectively, these have become known as Criminal Justice Liaison and Diversion (CJLD) services. 
The results of previous studies, both in the UK and the US, have provided mixed evidence for the effectiveness of CJLD services (Pakes \& Winstone, 2010; Scott et al, 2013). This may be due to a number of factors, including differences in location, staffing, nature and delivery of the various interventions, as well as methodological/design differences. Furthermore, the continued development of CJLD services such as those currently being trialled in England (NHS England, 2014a) has significant resource implications. It is important, therefore, to assess the effectiveness of these services to ensure that they (and future service developments) are appropriately targeted and are effective, both in terms of helping/supporting the MDOs and in sustaining public confidence in the judicial system.

To date, relatively few CJLD services have been evaluated and there is a marked lack of comparative or controlled research evaluations. Although the new Liaison and Diversion model for England is likely to address many of the questions around the design and implementation of these services, it is likely to be some time before definitive results are available (NHS England 2014a). Consequently, at the moment little is known about the effectiveness of these services and what constitutes an appropriate service response for this vulnerable and often socially excluded group. The aim of this study is to contribute to the growing body of literature on CJLD by employing a comparative methodology to assess the effectiveness of a CJLD service in terms of its ability to link offenders to health and social services and to improve their mental health.

\section{The Belfast service}

The Belfast screening, assessment and referral service for MDOs is based in a busy city-centre police station which operates under the Police and Criminal Evidence (Northern Ireland) Order 
(1989). The station provides a specialist setting for the treatment, questioning and identification of mentally disordered suspects. The service is based on the Diversion At the Point of Arrest (DAPA) model (Riordan et al, 2000) and provides a mental health assessment at the earliest point of contact with the Criminal Justice System (CJS) and, where appropriate, provides guidance and referrals to local health and social services. It is provided 7 days a week by two experienced Community Mental Health Nurses (CMHNs) who have completed a two-year RCN accredited Diploma in Forensic Health Care. The CMHNs are available from 7am to 7.30pm Monday to Friday and from $7 \mathrm{am}$ to $3 \mathrm{pm}$ on weekends. The service receives support from forensic psychiatry on a case-by-case basis where the CPNs deem that a Psychiatrist's professional input is required. The nurses also liaise with GPs who have undertaken specialist forensic training (Forensic Medical Officers or FMOs), police officers, court officials, and probation officers, as well as a range of local health and social services professionals and voluntary agencies.

The CMHNs screen the Custody Record Forms (CRFs) of all detainees using criteria originally developed for use in the Birmingham Court Diversion Scheme (Kennedy and Ward, 1992) including: (1) a history of mental illness and/or learning disability; (2) an 'odd' or unusual crime such as eccentric behaviour leading to a referral to the police; or, (3) a violent crime. In addition, detainees may be referred to the service for a mental health screening assessment by, for example, an FMO, custody sergeant or Resident Magistrate. The CRF screening facilitates the identification of anyone who may have a mental health problem. Everyone who meets one or more of the above criteria is invited by a CMHN to participate in an assessment. Following assessment, a report is prepared which includes recommendations for follow-up treatment and support. This report is made available to the court, arresting officer, defendant's solicitor and the Public Prosecutions Service (PPS). 


\section{Methods \\ Participants and settings}

The study employed a prospective follow-up design with a comparator group. Study participants $(\mathrm{N}=158)$ were interviewed upon being detained in the police station and approximately six months later. The CJLD service participants (intervention group) $(n=68)$ were recruited by the two CMHNs. All detainees took part in an initial interview to ensure that their health and welfare needs were met during their time in custody, after which the CMHNs completed a mental health assessment with all positively screened detainees using the measures described below. During routine assessments, $\mathrm{CMHNs}$ asked detainees if they would be willing to meet with a researcher in approximately six-months. Detainees who provided their written informed consent were admitted to the study.

The comparator group $(n=90)$ comprised similar detainees in a comparable police station in a neighbouring city which did not have access to the service. A researcher was based in this police station on a full-time basis (7 days per week). Detainees who provided written informed consent were assessed using the measures described below. Sample size calculations were based on our earlier work (McGilloway and Donnelly, 2004) and a sample size of 71 in each group was estimated to be sufficient to detect a difference of 5 points on the Brief Psychiatric Rating Scale, assuming a standard deviation of 10.67 points, $80 \%$ power and a significance level of $5 \%$.

\section{Measures}


A battery of mental health measures was employed to facilitate a comprehensive and relatively brief assessment. These measures have been employed in previous work with this population (McGilloway \& Donnelly, 2004).

(1) A Profile Form (PF) included: socio-demographic information; primary diagnosis; 'institutional' history; offence history; police and court 'disposal'; and, recommended follow-up service(s).

(2) Screening Questionnaire (SQ)

A Screening Questionnaire (SQ) administered to all participants comprised: (a) one question about head injury; (b) two-questions for detecting depressive symptoms in the previous month (Whooley et al, 1997 on which a positive response to either question is indicative of a positive result; and (c) the Psychosis Screening Questionnaire (PSQ) (Bebbington and Nayani, 1995) ( $\alpha=.74)$.

(3) Learning Disability Questionnaire (LDQ)

Detainees were also screened for a possible learning disability using the four-item Learning Disability Questionnaire (LDQ) (Lyall et al, 1995).

(4) Assessment of Risk Form (ARF)

An Assessment of Risk Form (ARF) comprised: (a) a checklist of selected items derived from the 'Psychopathy Checklist' (Hare, 1980) $(\alpha=.84)$ and other standard risk assessment measures; (b) eight questions about the respondent's attitude to self-harm and causing harm to others; and, (c) the 'Dangerous Behaviour Checklist' adapted from the Problems 
Questionnaire (Clifford, 1987). Information on previous incidents of violence was obtained from the detainee and from criminal records.

(5) Brief Psychiatric Rating Scale - Expanded version (BPRS-E) Participants completed the 24-item BPRS-E (Ventura, Lukoff\& Nuechterlein, 1994) $(\alpha=$ .81) which was developed to assist with symptom assessment during clinical trials. The measure comprises: 11 self-report items; 4 items rated on the basis of self-report and observed behaviour; and 9 items based only on observed behaviour.

(6) Self-Report questionnaires

Respondents were asked, to self-complete: the General Health Questionnaire-12 (Goldberg, 1978) $(\alpha=.90)$, a measure of minor psychiatric morbidity; the 10 -item Alcohol Use Disorders Identification Test (AUDIT) (Saunders et al, 1993) $(\alpha=.86)$ which was used to screen for harmful alcohol consumption; the Drug Abuse Screening Test (DAST) Short Form (Skinner, 1992) $(\alpha=.92)$ which provides a measure of problems associated with drug misuse and; the Duke Social Support and Stress Scale (DUSOCS) self-report measure (Parkerson, Michener \& Wu, 1989) $(\alpha=.70)$ which assessed the support provided by family and non-family members. The researcher provided assistance if respondents were unable to self-complete these measures.

\section{Results}

\section{Profile of the sample}


Sixty-eight detainees (43\%) who received an assessment from the CJLD service and 90 detainees (57\%) who attended the comparator station, agreed to participate in the study. Follow-up interviews were completed with 29 CJLD service users (43\%, 29/68) and 41 comparator participants $(45 \%, 41 / 90)$.

The profiles of both groups were broadly similar on a range of variables including: age, sex, marital status, living situation, employment status, criminal history and, institutional history. Detainees in both police stations were typically unemployed, single males in their late twenties or early thirties who were most likely to be living alone or with their parents. The majority of detainees in both study groups reported having some form of 'institutional history' including a previous prison sentence $(48 \%, 77 / 158)$ and/or an admission to psychiatric inpatient care $(46 \%$, 73/158). More than three-quarters of participants stated that they had previous contact with psychiatric services $(79 \%, 125 / 158)$, most of whom $(62 \%, 98 / 158$,$) reported that they had, at$ some stage, been treated by a psychiatrist.

\section{Criminal History}

All but 7 detainees $(95 \%, 151 / 158)$ had one or more previous convictions with the median number for CJLD service users being lower than comparator detainees (Table 1). A Mann-Whitney test found no significant differences $(p>0.05)$ between the number of previous convictions experienced by CJLD service users and comparator station users. More than half of the detainees $(53 \%, 84 / 158)$ were arrested for 'offences against the person'; this includes assaults, threats to kill and possession of an offensive weapon. Detainees were often charged with more than one offence and acquisitive offences (e.g. theft or burglary) were the second most common offence category $(28 \%, 44 / 158)$ (Table 1$)$. 


\section{Table 1 about here}

\section{Preliminary screening and assessment}

The screening of all 158 participants indicated that approximately one in five people $(21 \%$, $34 / 158)$ self-reported that they had 'definitely' $(n=22)$ or 'possibly' $(n=12)$ sustained a head injury in the past (there were no significant between-group differences). However, there was sufficient information available in only seven cases to suggest that a full psychological assessment was required. Screening for depression found that most CJLD $(81 \%, 55 / 68)$ and comparator participants $(88 \%, 79 / 90)$ had experienced symptoms indicative of depression during the previous month whilst approximately one quarter $(26 \%, 41 / 158)$ responded positively to one or more of the three LDQ key questions. For example, most respondents reported having difficulty in reading or writing (36/41) whilst approximately half indicated that they had also received additional help at school due to difficulties in learning $(54 \%, 22 / 41)$. Only four of those who responded positively to these questions were assigned a formal diagnosis of Learning Disability.

\section{Mental health status}

On average, the BPRS-E scores obtained by both the CJLD and comparator participants indicated the presence of mild to moderate levels of psychiatric disorder. Changes in psychiatric symptoms were also assessed using the BPRS-E (Table 2). Initial baseline assessments indicated significantly higher comparator group scores on the BPRS-E (median score of 39) than in the CJLD group median score of 35.5). Further examination of baseline scores using Mann-Whitney tests indicated that there were significant differences between the two groups on self-report items only $(z=-6.49, \mathrm{p}=.001)$. Therefore, it can be concluded that the differences in 'response' only 
items provided by the two groups of detainees were sufficient to cause a significant difference in the overall BPRS-E score at the baseline assessment. These differences were not observed at follow-up. Although again, 'comparator' group detainees reported higher BPRS-E scores on average (median score of 42 vs. a median of 36 for CJLD participants), this difference was not statistically significant (Table 2). There were no statistically significant within-group differences in BPRS-E scores during the course of the study; neither were there any statistically significant changes in psychiatric symptomatology for either group during the study period, although both groups reported lower BPRS-E scores at follow-up, indicating some improvement in overall psychiatric symptomatology.

\section{Table 2 about here}

There were no statistically significant differences between the two groups in GHQ scores at either baseline or follow-up (Table 3). However, a within-group comparison showed that both groups reported statistically significant improvements in median GHQ scores during the study (CJLD: $z=-$ 2.364, $\mathrm{p}=.018$; Comparator group; $z=-3.450, \mathrm{p}=.001$ ) indicating improvements in non-specific psychiatric morbidity during the study period.

\section{Table 3 about here}

\section{Self-reported alcohol and drug abuse}

No significant differences were noted between the two groups at baseline on alcohol abuse (Table 4); the median scores for both groups were substantially higher than the cut-off for possible problem drinking, with almost half of each group recording scores in the most severe category 
(CJLD; 48\%, 33/68; comparator 49\%, 44/90). A similar pattern was found at follow-up and again, there were no significant differences between the two groups. A within-group analysis also indicated no statistically significant improvements in either group during the study.

\title{
Table 4 about here
}

\begin{abstract}
With respect to drug use, there were no significant differences between the two groups at baseline or follow-up (Table 5). However, drug use had increased amongst both the CJLD and comparator clients at the six-month follow-up, although; this difference was statistically significant only for the comparator group $(z=-3.036, P=.002)$.
\end{abstract}

\section{Table 5 about here}

\section{Social Support}

There were no significant between-group differences at either time-point on measures of social support (Table 6). At baseline, comparator participants were significantly more likely to report that their relationships with other people caused them stress when compared to the CJLD detainees $(z=-2.099, \mathrm{p}=.036)$, though this difference was no longer significant when the two groups were compared at follow-up. On average, the social stress scores increased during the study period though, again, this difference was statistically significant only amongst comparator group participants $(z=-2.212, \mathrm{p}=.027)$.

\section{Table 6 about here}




\section{Discussion}

The aim of this study was to examine the effectiveness of a screening, assessment and referral service for MDOs. Most CJLD services have not been subjected to rigorous evaluation and few existing evaluations have employed a comparative methodology. The findings reported here demonstrate that the Belfast CJLD service successfully identified and assessed a large number of MDOs within the CJS. However, in terms of changes in mental health status, those who received the assessment and referral service did not fare better in terms of their overall mental health, than the treatment-as-usual comparator group.

At baseline, participants from both groups were similar on most assessed variables. In line with other studies, they were typically male, single, unemployed and in their late twenties or early thirties (e.g. James et al, 2002). As with previous research (e.g. Senior et al, 2013; Callahan, 2013) most were known to psychiatric services with the majority in both groups, reporting that they had previously met with a psychiatrist and/or attended a psychiatric hospital. Thus, four out of every five respondents had some previous contact with psychiatric services, though it appears that they had previously been unable to obtain a service response capable of meeting their needs, or were insufficiently motivated to engage with existing services (Dyer, 2013; James et al, 2002; Pakes \& Winstone, 2010). Nonetheless, the service was targeting few people previously unknown to services.

\section{Criminal history and outcomes}

Many participants reported lengthy criminal histories, suggesting that criminal activity was an established pattern of behaviour. This finding also suggests that, had sufficient mental health services been available within prisons, this period of detainment may have offered an opportunity 
for MDOs to engage more with services (Levy, 2007; Siva, 2010). However, it should be noted that MDOs often reported that they had received multiple short custodial sentences which may have limited their opportunity to engage effectively with prison-based services. Where information on outcomes was available, it was clear that most participants were 'processed' by the police and entered the CJS. There was no evidence that the police or court service considered the CJLD service mental health report when processing cases.

\section{Changes in mental health status}

At baseline, both groups reported depressive symptoms during the previous month. A smaller group also responded positively to one or more questions on the LDQ; this group, for the most part, reported that they had difficulty reading and writing, though they believed that this was due to dyslexia and/or not having attended school regularly rather than a learning disability per se. Only a small number of participants had received a formal diagnosis of a learning disability.

BPRS scores revealed no significant change in severe psychiatric symptomatology over time or between groups. At baseline, comparator detainees reported significantly worse mental health than CJLD detainees, but additional analysis showed that this was true for self-report items only. It is not clear why clients who received the service, obtained better outcomes on these items than comparator participants. At follow-up, both groups reported improved outcomes, although this was not statistically significant. This suggests that those clients who participated in the CJLD service did not experience the structured support and monitoring considered necessary to effect significant changes in their psychosocial health and well-being (Cosden et al, 2005; McNiel \& Binder, 2007). This is borne-out by follow-up data which found that only seven $(24 \%, 7 / 29)$ CJLD service participants reported acting upon the advice they had received from the CJLD service. A 
key consideration for any CJLD service is how best to foster ongoing engagement between MDOs and service providers. In this study, many MDOs were unwilling or unable to engage with treatment recommendations and for the same reason, Parsonage et al. (2009) stated that, in the absence of 'assertive interventions', drop-out rates from CJLD services were likely to be high.

Although it may be controversial (Canvin et al, 2013; Molodynski et al, 2010), the future development of CJLD services should examine the use of 'conditionality' in criminal charging and courts may have to be more pro-active in their use of appropriate sentencing options. For example, the Criminal Justice Act (2003) introduced a Community Order which allows the court to provide a community sentence with twelve different requirements; an offender can be ordered to complete one, or a combination of requirements as part of their community sentence. One of these is a Mental Health Treatment Requirement (MHTR) where, with the offender's consent, a court can require the person to see a mental health professional; similar requirements can be employed to encourage participants to engage in alcohol and or drug treatment programs. MHTRs are often combined with a 'supervision requirement' to support the MDO and reinforce the need to attend treatment (Bradley et al, 2009). However, Ministry of Justice (2008) statistics show that this sentencing option is not commonly employed and further research is required to ascertain how effective such sentencing options may be in helping MDOs engage with treatment and also to understand why judges and magistrates do not employ the full range of community sentencing options available to them (Brooker et al, 2009).

In order to build an evidence base capable of supporting the development of CJLD services, future studies should define both the internal workings of the service (i.e. service model, eligibility criteria, staffing, methods of working etc.) as well as external factors such as referral services and 
CJS protocols (i.e. which outline the circumstances under which the CJS will permit diversion and any conditions placed on diversion by the CJS (e.g. conditionality). The findings of the current study also highlight a need for future work to provide information on various CJLD service elements and to monitor the MDOs' compliance with treatment recommendations.

Both groups reported significant improvements in their overall levels of psychological distress during the study period. This may be due to the fact that many participants are detained when experiencing a crisis and respond in a manner which contributes to their arrest. During the follow-up period, participants were re-assessed during a period of stability and were less likely, therefore, to respond negatively to GHQ items. Furthermore, at baseline, detainees had been arrested, charged and detained in the police station whereas, during follow-up interviews, respondents were assessed in the community. The change in circumstance and location may have influenced the responses provided and this may have implications for future follow-up studies. Again, similar improvements in both groups raises questions about the extent to which this service facilitated an improvement in the mental health outcomes of respondents.

\section{Alcohol and drug use}

A further challenge was the management of detainees who were frequently heavily intoxicated. Alcohol is an important contributory factor in criminal activity (Gunn, 2000; Greenfield, 1998) and both groups reported similarly high levels of problem drinking at both time points, whilst a substantial proportion were in the most severe category. The lack of any significant change at follow-up is not unexpected perhaps, in that the ability of a CJLD service to effect change on a 'chronic' condition such as alcohol abuse is questionable, given that its primary role is to direct people toward existing services. For example, current service provision in $\mathrm{NI}$ is based largely on a 
client's willingness to engage with, often heavily over-subscribed, addiction services. It is unlikely that advice provided by the CJLD service would offer sufficient motivation for detainees to engage with these services.

Reassuringly perhaps, the levels of reported drug use in both groups were lower than those reported elsewhere (McNiel \& Binder, 2007; James et al, 2002) and few participants reported severe levels of drug misuse. Both groups reported an increased level of drug misuse at follow-up, although this was significant only amongst comparator group participants. This may be due to the presence of a social desirability bias at baseline, with detainees reluctant to discuss illegal drug use within a criminal justice setting.

\section{Social support \\ Participants in both groups reported low levels of social support and low levels of social stress at baseline. Study participants were often socially isolated while most did not see 'significant others' in their lives as their carers. Few felt that they needed someone to care for them and most reported that, when faced with a crisis, they kept this information to themselves. The reluctance to perceive other people as supportive, or as carers, may be due to most detainees reporting minor mental illnesses. On the whole, having few social supports was not a concern for respondents.}

\section{Study limitations}

Similar to previous studies with this client group, recruiting and retaining participants was challenging (e.g. Chung et al, 1999) and we were unable to recruit the required sample size of 71 in the intervention group. The follow-up (six-month) period was also short and may not have 
allowed sufficient time for changes to materialise, although it should be noted that fewer than one-in-four participants reported following the advice they received from the CJLS service. In addition, it is not known precisely what happened to either the intervention or control groups during the six-month follow-up period in terms of the nature of their contact (or otherwise) with services as well as other relevant aspects of their lives. Most CJLD services are 'stand-alone' services which identify MDOs and place them in the care of existing services, yet the outcomes used to assess their effectiveness tend to reflect a process of longer-term engagement with mental health services. Arguably, some or all of the outcomes employed in this and other studies may not be ideal for ascertaining the effectiveness of a service which is configured to work in isolation from mainstream service providers (Pakes \& Winstone, 2010; Senior et al, 2011).

\section{Conclusion}

It is important to note that the CJLD service that was the focus of the present study was developed only to carry out mental health assessments and to 'signpost' positively screened clients to existing services within the community. The effectiveness of using CJLD services as a mechanism for accessing treatment is equivocal and appears to be model-dependent. Available evidence suggests that providing direct access to services and overseeing compliance through the CJS may be more successful than 'stand-alone' services such as that described here (Pakes \& Winstone, 2010; Scott et al, 2013). However, this kind of approach would require an overhaul of many existing services (including the Belfast-based service) with attendant resource implications, whilst rigorous formative and summative research, such as that being undertaken currently (NHS England, 2014a) would also be required to inform such developments and evaluate the nature and extent of any change in outcomes over time. 
The future of diversion as a policy rests on the belief that the identification of MDOs and the provision of treatment will prevent future offending. However, the continued failure to provide high quality evidence to support this belief suggests that public support and, as a consequence, political goodwill, cannot be indefinitely sustained despite a need to respond positively to offenders with mental health needs. Policy reports in the UK (Bradley, 2009; Parsonage et al, 2009) call on the government to provide a national policy to direct service development for MDOs and it is hoped that the NHS pilot initiatives currently underway will be helpful in this regard (NHS England, 2013a; NHS England, 2014b).

At present, current provision in the UK and elsewhere is characterised by considerable variation in how services are configured while many schemes work in isolation and are insecurely funded (Sainsbury Centre for Mental Health, 2009). In addition, existing evidence is characterised by a lack of reliable descriptive information coupled with largely inadequate quantitative information on the workings of CJLD services, particularly in terms of outcomes, effectiveness and costeffectiveness. Again, it is hoped that the NHS England studies of clearly specified services will help to address some of these gaps in our knowledge.

There is also a need, going forward, to recognise that CJLD services operate at the interface of two highly complex systems; the Criminal Justice System and Health and Social Services (Parsonage et al, 2009). Therefore, the diversion of MDOs in its various forms should be seen as a complex intervention (Wolff \& Pogerzelski, 2005) requiring a stronger theoretical base (than is currently available) that links service structures, processes and outcomes in an iterative framework of development, monitoring, formative testing and rigorous controlled evaluation (Craig, et al, 2008). Governments, both nationally and internationally, remain committed to the principle of 
diversion and are continuing to invest in research to underpin the development of CJLD services (e.g. Senior et al, 2011; NHS England, 2014a; Steadman et al, 2014). It is only through the commissioning of such research that we can hope to develop the kinds of appropriate, effective and timely services that are required to meet the complex needs of this vulnerable and often socially excluded group.

Financial support: Funding was provided by the National Institute of Health Research.

Conflict of interest: The authors declare that they have no competing interests.

Ethical Standards: The authors assert that all procedures contributing to this work comply with the ethical standards of the relevant national and international committees. Full ethical approval was provided by Office for Research Ethics Committees Northern Ireland. 


\section{References}

Bebbington, P. and Nayani, T. (1995). The Psychosis Screening Questionnaire. International Journal of Methods in Psychiatric Research, 5, pp.11-

Bradley, K. (2009). The Bradley Report: Lord Bradley's Review of People with Mental Health Problems or Learning Disabilities in the Criminal Justice System. Department of Health: London.

Broner, N., Lattimore, P.K., Cowell, A.J. and Schlenger, W.E. (2004). Effects of Diversion on Adults with Co-Occurring Mental IIIness and Substance Use: Outcomes for a National Multi-Site Study, Behavioral Sciences and the Law, 22, pp. 519-541.

Brooker, C. and Ullman, B. (2009). Inside Out: Solutions for Mental Health in the Criminal Justice System. Policy Exchange: London.

Callahan, L., Steadman, H.J., Tillman, S., and Vesselinov,R. (2013). A Multi-Site Study of the use of Sanctions and Incentives in Mental Health Courts. Law and Human Behavior, 37(1), pp1-9.

Canvin, K., Rugkasa, J., Sinclair, J., and Burns T. (2013). Leverage and other Informal Pressures in Community Psychiatry in England. International Journal of Law and Psychiatry, 36(2) pp 100-106.

Chung, M.C., Cumella, S., Wensley, J., and Easthope, Y. (1999). A Follow-up Study of Mentally Disordered Offenders after a Court Diversion Scheme: Six-Month and One-Year Comparison, Medicine, Science and the Law, 39(1), pp. 31-37.

Clifford, P. (1987). The Problems Questionnaire. Research and Development for Psychiatry: London.

Cosden, M., Ellens, J., Schnell, J. and Yamini-Diouf, Y. (2005) Efficacy of a Mental Health Treatment Court with Assertive Community Treatment, Behavioral Sciences and the Law, 23, pp. 199-214. 
Craig P, Dieppe P, Macintyre S, Michie S, Nazareth I, Petticrew M (2008). Developing and Evaluating Complex Interventions: the new MRC Guidance. British Medical Journal, 337, pp. 979983.

Cuddeback, G.S., Morrissey, J.P., \& Cusack, K.J. (2008). How many Forensic Assertive Community Treatment Teams do we Need? Psychiatric Services, 59(2), pp. 205-208.

Dyer, W. (2013). Criminal Justice Diversion and Liaison Services: A Path to Success? Social Policy and Society, 12(1), pp34-45

Exworthy, T. and Parrott, J. (1997). Comparative Evaluation of a Diversion from Custody Scheme. Journal of Forensic Psychiatry, 8(2), pp. 406-416.

Goldberg, D. (1978) Manual of the General Health Questionnaire. NFER-Nelson: Windsor.

Greenfield, L.A. (1998) Alcohol and Crime: An Analysis of National Data on the Prevalence of Alcohol Involvement in Crime. Bureau of Justice Statistics: United States.

Gunn, J. (2000). Future Directions for Treatment in Forensic Psychiatry. British Journal of Psychiatry, 176, pp. 332-338.

Hare, R.D. (1980). A Research Scale for the Assessment of Psychopathy in Criminal Populations. Personality and Individual Differences, 1, pp. 111-119.

James, D.V., et al (2002). Outcome of Psychiatric Admission through the Courts. Home Office, London.

Kennedy, N.M.J. and Ward, M. (1992). Training Aspects of the Birmingham Court Diversion Scheme. Psychiatric Bulletin, 16(10), pp. 630-631. 
Lamb, HR., Weinberger, LE. And Reston-Parham, C. (1996) Court Intervention to address the Mental Health Needs of Mentally Disordered Offenders, Psychiatric Services, 47(3), pp10971106.

Levy, M. (2007). International Public Health and Corrections: Models of Care and Harm Minimization. In, Public Health Behind Bars from Prisons to Communities (Ed. R. B. Greifinger). Springer, NY.

Lyall, I., Holland, A.J., Collins, S. and Styles, P. (1995). Incidence of Persons with a Learning Disability Detained in Police Custody: A Needs Assessment for Service Development. Medicine, Science and the Law, 35, pp. 61-71.

McGilloway, S., and Donnelly, M. (2004). Mental Illness in the UK Criminal Justice System: A Police Liaison Scheme for Mentally Disordered Offenders in Belfast. Journal of Mental Health, 13(3), pp. 263-275.

McNiel, D.E. and Binder, R.L. (2007). Effectiveness of a Mental Health Court in reducing Criminal Recidivism and Violence. American Journal of Psychiatry, 164(9), pp. 1395-1403.

Molodynski, A., Rugkasa, J., and Burns, T. (2010). Coercion and Compulsion in Community Mental Health Care. British Medical Bulletin, 95, pp105-119.

Moore, M.E. and Aldigé Hiday, V. (2006). Mental Health Court Outcomes: A Comparison of ReArrest and Re-Arrest Severity between Mental Health Court and Traditional Court Participants. Law and Human Behavior, 30, pp. 659-674.

NHS England Liaison and Diversion Programme (2014a). Liaison and Diversion Operating Model 2013/14. NHS England: London.

NHS England Liaison and Diversion Programme (2014b). Liaison and Diversion Standard Service Specification. NHS England: London. 
Pakes, F. and Winstone, J. (2010). A Site Visit Survey of 101 Mental Health Liaison and Diversion Schemes in England, The Journal of Forensic Psychiatry and Psychology, 21(6), pp. 873-886

Parkerson, G.R., Michener, J.L. and Wu, L.R. (1989) Associations Among Family Support, Family Stress and Personal Functional Health Status, Journal of Clinical Epidemiology, 42, pp. 217-229.

Parsonage, M., Khanom, H., Rutherford, M. et al (2009). Diversion: A Better way for Criminal Justice and Mental Health. Sainsbury Centre for Mental Health: London.

Riordan, S., Wix, S., and Kenny-Herbert, J., (2000). Diversion at the Point of Arrest: Mentally Disordered People and Contact with the Police. Journal of Forensic Psychiatry, 11, pp. 683-690.

Saunders, J. B., Aasland, O. G., Babor, T. F., de la Fuente, J. R. and Grant, M. (1993) Development of the Alcohol Use Disorders Identification Test (AUDIT): WHO Collaborative Project on Early Detection of Persons with Harmful Alcohol Consumption — II. Addiction 88, pp. 791-804.

Scott, D., McGilloway, S., Dempster, M., Browne, F and Donnelly, M. (2013). Effectiveness of Criminal Justice Liaison and Diversion Services for Offenders with Mental Disorder: A Review, Psychiatric Services, 1(6), pp.843-9

Senior, J., Lennox, C., Noga, H. and Shaw, J. (2011). Liaison and Diversion Services: Current Practices and Future Directions, Offender Health Research Network, http://www.ohrn.nhs.uk (accessed May 2015).

Siva, N. (2010). New Hope for Prison Health in the UK. The Lancet, 375 (9713), pp447-448.

Skinner, H.A. (1982). The Drug Abuse Screening Test. Addictive Behaviours, 7, pp. 363-371.

Ventura, J., Lukoff, D., and Nuechterlein, K.H. et al (1994). Brief Psychiatric Rating Scale Expanded Version (4.0) scales, anchor points and administration manual. International Journal of Methods in Psychiatric Research, 3, pp. 227-243. 
Whooley, M.A., Avins, A.L., Miranda, J. and Browner, W.S. (1997). Case-finding Instruments for Depression. Two Questions are as Good as Many. Journal of General Internal Medicine, 12, pp. 439-445.

Wolff, N. and Pogorzelski, W. (2005). Measuring the Effectiveness of Mental Health Courts: Challenges and Recommendations, Psychology, Public Policy and the Law, 11(4), pp. 539-569. 